\title{
Visual Alarm Device
}

National Cancer Institute

\section{Source}

National Cancer Institute. Visual Alarm Device. NCI Thesaurus. Code C49822.

A device designed to signal the occurrence of a particular event in a way that can be seen. 